\title{
Effect of unsteady flow conditions on scour features at low-head hydraulic structures
}

\author{
Michele Palermo ${ }^{\mathrm{a}^{*}}$ and Stefano Pagliara ${ }^{\mathrm{a}}$ \\ ${ }^{a}$ DESTEC-Department of Energy, Systems, Territory and Construction Engineering, \\ University of Pisa, Via Gabba 22, 56122 Pisa, Italy
}

\begin{abstract}
The study of scour mechanism downstream of low-head control structures is a fundamental topic for hydraulic engineers. Generally, the analysis of the scour process is conducted under steady flow conditions, assuming that the maximum discharge is occurring for sufficient time to reach the equilibrium scour configuration. Nevertheless, in rivers the scour process generally occurs in correspondence with a flood event, which is characterized by discharge varying with time. This last condition is still less studied and analyzed in terms of effects on bed morphology. Researchers mainly focused on the maximum scour depth assuming that it occurs in correspondence with the peak discharge, but they rarely took into account the evolution of the scour process under unsteady flow conditions. The aim of the present paper is to analyze the evolution of scour morphology under unsteady flow conditions, and compare it with that obtained under steady flow conditions. In particular, three structure typologies were tested: a stepped gabion weir with upstream impermeable filtering layer, a straight rock sill, and a curved rock sill. The results showed that the scour phenomenon deeply depended on inflow conditions. Nevertheless, it was also shown that the equilibrium morphology of the downstream stilling basin is essentially the same under both unsteady and steady flow conditions if the duration of the unsteady event is enough long.
\end{abstract}

Keywords: Hydraulic models; Low-head structures; Scour process; Unsteady flow.

\section{Introduction:}

The scour mechanism occurring downstream of low-head control structures is an important topic that has been widely analyzed in recent decades. In particular, the analysis mainly focused on the hydraulics and the scour characteristics in the stilling basin. Low-head structures have been found effective in controlling sediment transport and, at the same time, they are able to guarantee a reduced impact on the ecosystem. Therefore, many traditional structures have been re-converted into more eco-friendly anthropic works, such as block ramps, rock grade control structures, stepped gabion weirs, cross-vane, W-weirs, etc.

\footnotetext{
${ }^{*}$ Corresponding author. Present address: DESTEC-Department of Energy, Systems, Territory and Construction Engineering, University of Pisa, Italy. Via Gabba 22, 56122 Pisa, Italy, Tel. +39 050 2217929; fax +39 050 2217730, E-mail address: michele.palermo@ing.unipi.it
} 
One of the first systematic studies investigating erosive process occurring in a movable stilling basin was conducted by Veronese (1937). The author analyzed the effect on the scour characteristics of the stilling basin geometry. Namely, he conducted a series of experimental tests in prototype channels to investigate the effect of symmetric enlargement of the stilling basin on scour morphology. More recently, Bormann and Julien (1991) analyzed several grade control structures configurations, varying both the model scale and the geometry of the structure itself. They concluded that the scour process depends on both the structure geometry and on the stilling basin characteristics. Based on the similarities between scour process due to plunging jets and downstream of grade control structures, Bormann and Julien (1991) and, successively, D'Agostino and Ferro (2004) showed that the diffusion length of the flow entering the stilling basin is a fundamental parameter. Furthermore, as it was also shown for scour due to plunging jets (see for example Rajaratnam, 1981; Rajaratnam and Macdougall, 1983; Breusers and Raudkivi, 1991; Hoffman and Verheij, 1997; Hoffman, 1998; Manso and Arumugam, 1985; Pagliara et al., 2010; Pagliara et al., 2012a), the geometry of the structure was found a significant parameter influencing the scour morphology because of the different entering flow inclinations. Among eco-friendly hydraulic structures, block ramps and rock chutes constitute a peculiar typology. Namely, they are characterized by a complex hydraulic behavior due to the rough sloped bed that contributes to dissipate an appreciable amount of energy (Pagliara and Palermo, 2011). In particular, these structure typologies exhibit some similarities with both stepped chutes and rock sills, in terms of both hydraulic behavior and dissipative mechanism. Nevertheless, the presence of a downstream mobile stilling basin contributes to amplify the energy dissipation, as a hydraulic jump generally occurs in correspondence with the structure. In general, eco-friendly structures exhibit substantial similarities in terms of scour process, due to their geometry that is characterized by relatively small dimensions (low height and/or mild surface slopes). In particular, a detailed analysis of the scour mechanism can be conducted in the case for which the structure is stable. Therefore, incipient movement conditions of the stones constituting the different eco-friendly structure typologies has received considerable attention (Parker et al., 1982; Whittaker and Jaggi, 1986; Robinson et al., 1997; Hoffmans, 2010). Furthermore, the main parameters influencing the scour phenomenon (tailwater, stilling basin material and geometry, protection sills, etc.) were carefully analyzed in order to understand the dynamics of the erosive mechanism both in clear water and live bed conditions (Pagliara and Palermo, 2011; Oertel et al., 2011; Pagliara et al., 2012b). The previously mentioned studies on block ramps were useful to understand the similarities and differences among other several low-head structures, as shown by Pagliara and Mahmoudi Kurdistani (2015) and Pagliara et al. (2016). In particular, stepped gabion weirs exhibit similarities with both stepped chutes and block ramp. They are characterized by different flow regimes: skimming, nappe and transition flow regimes. In addition, these 
different flow regimes deeply influence the scour mechanism in the downstream stilling basin. Pegram et al. (1999), Peyras et al. (1992) and Pagliara and Palermo (2013) analyzed this structure typology in detail. In particular, Pagliara and Palermo (2013) focused on the scour mechanism occurring downstream of stepped gabion weirs and rock grade control structures classifying the onset conditions of the different flow regimes (see also Rajaratnam, 1990; Essery and Horner, 1978; Peyras et al. 1992; Ohtsu et al. 2004). Namely, Pagliara and Palermo (2013) analyzed both the hydraulics and the scour process downstream of different stepped gabion weir configurations. They studied four structure configurations: permeable and impermeable isolated structures and structures with both permeable and impermeable upstream filtering layer having the same height of the stepped gabion weir. Their analysis was conducted for constant discharges up to the equilibrium scour conditions. Similarly, rock sills share similarities with other low-head hydraulic structures, including rock chutes, W-weirs, Jhook, etc. In particular, rock sills can assume different shapes according to their hydraulic functioning and the location in which they are inserted. Detailed studies on this type of structure were conducted by Bhuiyan et al. (2007) and Scurlock et al. (2011). They proved that $3 \mathrm{D}$ rock structures can substantially improve fish habitat and, at the same time, they can dissipate a relevant amount of flow energy. Therefore, in this study two different types of rock sills were taken into consideration, i.e., straight rock sills (which are common in river restoration projects) and curved rock sills (which can be considered representative of a larger variety of 3D low-head structures). The aim of the present paper is to analyze the hydraulics and the scour evolutions in the presence of both stepped gabion weirs and rock sills under unsteady flow conditions. In addition, this paper aims to answer to the following questions:

1) Under unsteady flow conditions, is it always correct to select the peak discharge to evaluate the maximum scour depth, using relationships valid for steady flow conditions?

2) If the answer to the previous question is negative (as it will be shown), is there a minimum duration of the unsteady flow event that can cause the same scour features of a steady event characterized by a constant discharge equal to the peak discharge? Equivalently, when should the peak discharge of the unsteady event occur to obtain the same maximum scour depth of a steady event with constant discharge equal to peak discharge?

To answer these two questions, experiments were conducted for different peak discharges varying both the time steps for the discharge increase/decrease and the total duration of the test. Furthermore, in order to minimize scale effects, experimental tests were conducted in two different channels and with different cohesionless materials. This analysis focused on the scour process evolution due to different flow conditions. It was experimentally proven that there is a significant similarity between the tested structures, i.e., it was shown that for certain 
inflow conditions, the non-dimensional time to reach the equilibrium configuration is essentially the same for all the low-head structure geometries tested in the present study. This implies that the answer to the first question is "no" (as it is valid for certain inflow conditions and not always), whereas the answer to the second question is "yes". Finally, an applicative example is provided in order to better illustrate the proposed methodology.

\section{Experimental Facilities:}

Two dedicated models were built at the hydraulic laboratory of the University of Pisa. Namely, experimental tests regarding stepped gabion weirs were conducted in channel 1 , which is characterized by the following geometric characteristics: $0.30 \mathrm{~m}$ wide, $0.60 \mathrm{~m}$ deep and $6 \mathrm{~m}$ long. Whereas experimental tests with rock sills were conducted in channel $2(0.50 \mathrm{~m}$ wide, $0.90 \mathrm{~m}$ deep and $8 \mathrm{~m}$ long). The stepped gabion weir was made of uniform rounded stones whose median diameter was $D_{50}=12 \mathrm{~mm}$. Stones were kept together using a wide mesh $(1 \mathrm{~cm} \times 1 \mathrm{~cm})$. The structure was built in layers (Figure 1) with step width $w_{s}$ and step height $h_{s}$ equal to $51.3 \mathrm{~mm}$. The total structure height was $H=154 \mathrm{~mm}$. A filtering layer, having the same height of the structure, was located upstream and constructed using the same material as the downstream stilling basin in channel $1\left(d_{50}=4.78 \mathrm{~mm}, d_{90}=5.7 \mathrm{~mm}\right.$, non-uniformity coefficient $\sigma=1.2$ and density $\rho_{s}=2645 \mathrm{~kg} / \mathrm{m}^{3}$, with $d_{x x}$ diameter of the stilling basin material for which $\mathrm{xx} \%$ is finer). In addition, the upstream filtering layer was made impermeable by using a covering steel sheet in order to simulate a real configuration that usually occurs in rivers when an upstream sediment layer becomes impermeable due to the presence of silt and clay intrusion between grains. Furthermore, two rock sill typologies were tested, i.e., straight and curved rock sill. Rock sills were made of crushed stones layers and shaped in such a way that the final configuration was either straight or curved. Namely, the median diameter $D_{50}$ of the stones constituting the sill was equal to $4.65 \mathrm{~cm}$ (non-uniformity coefficient $\sigma=1.3$ and density $\rho_{s}=2450 \mathrm{~kg} / \mathrm{m}^{3}$ ), whereas the stilling basin material adopted in channel 2 was much finer that than of Channel $1\left(d_{50}=2 \mathrm{~mm}\right.$, non-uniformity coefficient $\sigma=1.22$ and density $\left.\rho_{s}=2214 \mathrm{~kg} / \mathrm{m}^{3}\right)$. The choice to adopt two different stilling basin materials allowed to establish that there is no influence of the bed material size on the scour evolution. Furthermore, also scale effects can be considered negligible as the kinetics of the erosive process was found essentially the same in both the channels and for all of the different tested structures. The curved rock sill was characterized by a non-dimensional curvature $R / B=0.5$, where $R$ is the curvature radius of the sill and $B$ the width of the channel. Figure 2 illustrates the rock sills simulated in channel 2. Experimental tests were conducted for different hydraulic conditions, i.e., different discharges $Q$ and different downstream tailwater levels $h_{0}$. In particular, the downstream tailwater level was not controlled, therefore for each discharge different tailwater 
levels occurred. Furthermore, the inflow discharges varied between 5 and 10 1/s for stepped gabion weirs and between 10 to $15 \mathrm{l} / \mathrm{s}$ for both curved and straight rock sills. Preliminary tests were conducted under constant discharge in order to obtain the references values of the main scour characteristics, i.e., $z_{\max }$ (maximum scour hole depth) and $l_{s}$ (axial scour hole length). Namely, selected tests were repeated two times for all the different tested structures in order to verify the accuracy of the measurements and the repeatability of the results. They allowed to assess that no significant differences in terms of both scour geometry evolution and equilibrium configuration can be detected under the same hydraulic conditions. The scour evolution was carefully surveyed and the values of the maximum scour depths at different instants $z_{\max }(t)$ were collected. More specifically, the scour hole profiles were recorded optically with a CCD camera and the image acquisition was controlled with a programmable timing unit to ensure an accurate time control from the test start (a similar methodology was adopted by Unger and Hager, 2006, and Pagliara et al., 2008, for scour evolution due to plunging jets). In the meantime, a sequence of high definition pictures was taken at different instants. In addition, at selected instants, the maximum scour depth was measured by using a $0.1 \mathrm{~mm}$ precise point gauge fitted with a $10 \mathrm{~mm}$ circular plate at its lower end. The combination of direct measurements of the maximum scour depth and the analysis of the images sequence allowed to reach an overall precision of $\pm 1 \mathrm{~mm}$. The same experiments were repeated varying the inflow conditions. Namely, the peak discharge $Q_{\max }$ of each experimental test was the same of the reference tests but it was reached by steps. For example, for stepped gabion weirs, the non-dimensional hydrograph reported in Figure 3 was adopted, in which $Q(t)$ is the discharge at the $i$-step. Namely, a triangular shaped hydrograph was selected to simulate the unsteady inflow conditions. The total duration of the discharge decreasing phase was double of the duration of the discharge increasing phase. In addition, the increasing phase was characterized by 8 discharge increase steps, whereas, the decreasing phase by 16 steps. Each $Q(t)$ was kept constant for a certain time step $\Delta t$. The minimum $\Delta t$ was set at $\Delta t_{\min }=1$ minute (in order to simulate and almost continuous discharge variation). Therefore, the same test was repeated for different $\Delta t$ time steps (i.e., $\Delta t=n \Delta t_{\min }$, where $n$ is a natural number varying between 1 and 12), but with the same peak discharge $Q_{\max }$, in order to analyse the effect of this parameter on the scour depth evolution. The total duration $t_{f}$ of each experimental test varied according to the selected $\Delta t$. For both straight and curved rock sills, the methodology adopted was essentially the same. But, in order to tests the effect of the selected methodology to reach the peak discharge on the scour evolution kinetics, the number of steps of the increasing phase of the hydrograph was set at 10 or 15 , therefore the number of steps in the decreasing phase was set at 20 or 30 , respectively. 


\section{Results and discussion:}

\subsection{Hydraulics of low-head structures}

The three different flow regimes of stepped gabion weirs are quite similar to those occurring on stepped chutes: Nappe Flow, Transition Flow and Skimming Flow regime. The Nappe Flow regime is characterized by flow plunging on the successive step (Figure 1a). The Skimming Flow regime (Figure 1c) is characterized by a coherent flow structure streaming on a pseudo-bottom. Horizontal axial vortexes occur between the steps and prominent flow recirculation takes place below the pseudo-bottom. This last regime also occurs on block ramps. For intermediate flow characteristics, the Transition Flow regime takes place (Figure 1b). Pagliara and Palermo (2013) classified the three flow regimes for the stepped gabion weirs and compared the onset hydraulic conditions of Skimming Flow regime with those relative to stepped chutes. Authors showed that significant similarities can be detected, even if they are peculiar structures characterized by two elements: the presence of the downstream mobile stilling basin, which contributes to vary the downstream conditions, and the structure permeability. In particular, the presence of a downstream hydraulic jump (either partially submerging the structure or completely located in the stilling basin) is an important element to be taken into consideration because of its effect on the filtration regime in the structure itself. Therefore, Pagliara and Palermo (2013) proposed a classification of the different flow regimes mainly depending on two non-dimensional parameters: $h_{s} / k$ and $h_{0} / H$, where $k$ is the critical depth. But experimental tests showed that the effect of $h_{0} / H$ on the flow regime is less significant if compared to that due to the parameter $h_{s} / k$. Thus, the key factor for the onset of the different flow regimes occurring in correspondence with this structure typology is represented by the parameter $h_{s} / k$, i.e., the Nappe Flow regime occurs for $h_{s} / k>1.5$, the Transition Flow regime occurs for $1.1<h_{s} / k_{c}<1.5$ and the Skimming Flow regime occurs for $h_{s} / k_{c}<1.1$.

The hydraulics of rock sills is quite similar to that of grade-control structures and it was exhaustively described by Bormann and Julien (1991). As the flow from the rock sill enters the tailwater a jet forms and the scour phenomenon occurs. Furthermore, according to the discharge, a vortex formation can take place in the scour hole. The applied shear stresses exceed the critical shear stress, starting to remove sediment from the scour hole and to transport them downstream. When the discharge increases, the vortex inside the scour hole shifts further downstream, partially flattening the formed ridge. It is worth noting that sediment forming the ridge can be transported both upstream and downstream according to the tailwater level. In fact, the tailwater level contributes to vary the impinging jet characteristics, as the jet diffusion length increases with the tailwater, eventually forming a reverse roller. This mechanism is at the base of the peculiar scour evolution behavior under unsteady flow conditions, i.e., the peak rate of scour do not always occur in correspondence 
with the peak discharge. In fact, in many tests the maximum scour depth occurred during the descending phase of the discharge. During this last phase, the discharge decreases, thus the jet impingement region shifts upstream. At the same time, the ridge, which has been flattened during the peak discharge, allows for sediment transport downstream. The eroded material is then transported downstream from the scour hole thus contributing to increase again the ridge height. This process lasts up to when the hydrodynamic force exerted on the particles no longer remove them from the scour hole. Based on the previous observations, it appears evident that, for longer duration of the unsteady event, the differences between the scour mechanisms occurring under constant discharge (equal to the peak discharge) and under unsteady flow conditions reduces.

\subsection{Scour depth evolution}

The scour evolution was carefully analyzed for all the tested structures. Figure 4 and Figure 5 illustrate the maximum scour depth variation with time, i.e., $z_{\max }(t)$ as function of the discharge $Q(t)$ for stepped gabion weirs and rock sills, respectively. In particular, Figure 4a reports $z_{\max }(t)$ as function of $Q(t)$ for maximum peak discharge $Q_{\max }=51 / \mathrm{s}$, whereas Figures 4b-c-d-e-f shows the same for tests with peak discharges equal to $Q_{\max }=6,7,8,9$ and $10 \mathrm{l} / \mathrm{s}$, respectively. Similarly, Figure $5 \mathrm{a}-\mathrm{b}$ shows $z_{\max }(t)$ vs $Q(t)$ for maximum peak discharges $Q_{\max }=10 \mathrm{l} / \mathrm{s}$ and $15 \mathrm{l} / \mathrm{s}$ for curved rock sills, whereas Figure $5 \mathrm{c}-\mathrm{d}$ shows the same for straight rock sills. In each graph, the evolution of the maximum scour depth is reported for different $\Delta t$ time step durations adopted for both the increasing and decreasing discharge phases. Finally, a point symbolizing the maximum scour depth measured in the corresponding reference tests (test with constant discharge equal to $\left.Q_{\max }\right)$ is reported in each graph $\left(z_{\max }\right.$; $Q_{\max }=\mathrm{cost}$ ), in order to compare the maximum scour depth values obtained under steady flow conditions with those relative to unsteady flow conditions. For each simulated hydrograph, it is evident that the duration of the time step $\Delta t$ (i.e., equivalently the total duration of the unsteady event) strongly affects the scour hole morphology and, in particular, the maximum scour depth $z_{\max }$. Namely, for low $\Delta t(<5$ minutes), generally, the maximum scour depth is

significantly less than that obtained in the corresponding reference test. Conversely, for $\Delta t>5$ minutes, generally, the maximum scour depth is comparable with that obtained in the reference test. In other words, in the tested conditions and for all the tested structures, it seems that if $\Delta t>\Delta t^{*}$, where $\Delta t^{*}=5$ minutes, no substantial differences occur in terms of scour hole features, under both steady and unsteady flow conditions. This evidence furnishes the answer to question 1) reported in the introduction. Namely, it is not always correct to assume the peak discharge to evaluate the maximum scour depth using relationships valid for steady flow conditions, as the maximum scour depth can be significantly smaller, according to the 
different inflow conditions. In addition, under unsteady flow conditions, the maximum scour depth could not occur in correspondence with the peak discharge for these tests, as clearly shown in Figure 4 and Figure 5. More specifically, especially for relatively low peak discharges, $z_{\max }$ could occur during the decreasing phase of the hydrograph, i.e., for $Q(t)<Q_{\max }$. This phenomenon is mainly due to two reasons and it is quite similar for all the tested structures, even if some differences can be pointed out between stepped gabion weirs and rock sills. In particular, for stepped gabion weirs, under unsteady flow conditions, different flow regimes occur in the same test. In addition, the downstream hydraulic jump tends to shift downstream during the increasing phase of the hydrograph, whereas it shifts towards the structure during the decreasing phase. Therefore, the movable stilling basin bed is cyclically modeled. During the increasing discharge phase, the downstream dune is flattened by the hydraulic jump which shifts downstream, i.e., its contribution in limiting the scour hole evolution partially vanishes. Conversely, under higher peak discharge, (see Figure 4e-f) the maximum scour depth occurring during the test can be slightly bigger than that occurring at the end of the test. In particular, the maximum scour depth during the test takes place when the skimming flow regime occurs on the structure. Therefore, during the decreasing phase of the discharge, the hydraulic jump shifts towards the structure and contributes to erode the upstream part of the scour hole transporting sediment downstream. The downstream part of the scour hole is partially replenished by the sediment eroded from the upstream part. In addition, for higher discharges, the time step duration $\Delta t$ required to obtain the same maximum scour depth occurring in the reference test becomes slightly bigger. Nevertheless, as mentioned, for practical purposes $\Delta t \geq 5$ minutes can be assumed as the minimum time step duration to get no differences in terms of maximum scour depth between unsteady and steady flow tests. Finally, especially for tests in which the peak discharge is high (therefore all the three flow regimes occur on the structure), three scour depth evolution kinetics can be detected: there is an initial phase (corresponding to nappe flow regime) in which the scour development is quite fast, followed by a phase in which the erosion kinetics reduces (corresponding to transition flow regime) and again by a phase in which the scour progress is fast (corresponding to skimming flow regime). This dynamic is essentially the same observed by Pagliara and Palermo (2013) under steady flow conditions. For rock sills, similar considerations can be done. Nevertheless, in this last case, the scour hole evolution is slightly different respect to the cases illustrated above. This is mainly due to the fact that rock sills do not protrude as high from streambed, therefore for low discharges, either the hydraulic jump does not even occur or it is a weak hydraulic jump with no roller. In addition, for higher discharge the hydraulic jump occurring downstream of the structure is generally submerged. Therefore, even if the kinetics of the erosive process (i.e., cyclic movement of the bed 
sediment) is essentially similar, some slight differences can be detected in terms of hydraulic functioning. Namely, the scour evolution dynamic appears more regular than in the presence of stepped gabion weirs, i.e., the eventual regression of the maximum scour depth, which was due to the hydraulic jump shifting in the stilling basin, is very slight or completely absent (see Figure 5a-d).

In order to generalize the previous observations, the scour depth evolution was reported in graphs with non-dimensional variables. Namely, the experimental data were reported in graphs $z_{\max }(t) / z_{\max }$ vs $Q(t) / Q_{\max }$, where $z_{\max }(t)$ is the maximum scour depth value in each test. In addition, also the interval duration relative to each discharge increment was made nondimensional as follows:

$$
\Delta T=\frac{\left[g\left(\left(\rho_{s}-\rho\right) / \rho\right) d_{50}\right]^{0.5} \Delta t}{k n}
$$

where $\Delta T$ is the non-dimensional time step, $g$ is the acceleration due to gravity, $k$ is the critical depth relative to the peak discharge and $n$ is a natural number varying from 1 to 12 . It means that for unsteady flow tests with same peak discharge, the non-dimensional time step duration is constant, as it depends only on $k$. In fact, according to what specified in section 2 , tests were conducted for different $\Delta t=n \Delta t_{\min }$, therefore whatever the value of the coefficient $n$ is, $\Delta t / n=\Delta t_{m i n}$. All the previous observations made for higher discharges applies for lower $\Delta T$, as shown in the Figure 6 (stepped gabion weirs) and Figure 7 (rock sills). In particular, from Figure $6 \mathrm{e}-\mathrm{f}$ it can be easily noted that, for lower $\Delta T$ values, the three different flow regimes occurring during the increasing discharge phase are clearly detectable. Furthermore, it is worth noting that the evolution of the maximum relative scour depth $z_{\max }(t) / z_{\max }$ appears quite similar for all the tests for which $n \geq 5$.

The previous analysis was further developed, considering the non-dimensional temporal evolution of the variable $z_{\max }(t) / z_{\max }$. Figure 8 (stepped gabion weirs) and Figure 9 report graphs in which the maximum relative scour depth $z_{\max }(t) / z_{\max }$ is plotted against the nondimensional time $T$, defined as follows:

$$
T=\frac{\left[g\left(\left(\rho_{s}-\rho\right) / \rho\right) d_{50}\right]^{0.5} t}{k n}
$$

in which $t$ is the time and $n$ is the coefficient specified above. In order to compare the unsteady and steady flow condition data, for steady flow conditions $n$ can be reasonably assumed equal to 1 . In fact, as specified above, $n=1$ corresponds to 1 minute time step 
variation of the discharge under unsteady flow conditions, i.e., almost a continuous variation of the discharge. In addition, for each test, the non-dimensional time $T_{\text {peak }}$ in which the peak discharge occurs is specified in the respective plots of Figure 8 and 9. The corresponding curve relative to the reference steady test is also reported in order to compare the behavior under steady and unsteady flow conditions. By observing the mentioned figures, it can be noted that, for all the structures tested, the trend of the evolution of the non-dimensional scour depths is quite similar for $n \geq 5$, thus confirming what discussed before, i.e., generally for $n \geq 5$, the equilibrium scour geometry due to unsteady flow conditions is essentially the same obtained under constant discharge equal to the peak discharge. In addition, the equilibrium configuration is reached for $T$ varying between 3500 and 5000 according to the different peak discharges tested. Therefore, for all the tested structures, we can reasonably assume that, for practical applications, the final equilibrium condition is reached for $T=T_{e q} \approx 4250$, i.e., an average value. Furthermore, the peak discharge is occurring for $2690<T_{\text {peak }}<4373$ for all the tested conditions. Also in this case, in order to furnish an indicative non-dimensional time for the peak discharge occurrence, we can assume the average value among those computed for all the tested structures, i.e., $T_{p e a k}^{*} \approx 3200$. Based on these observations, the second question proposed in the introduction can be answered. Namely, this study showed that there is a minimum duration of the unsteady flow event which allows to get the same equilibrium morphology occurring during an event characterized by a constant discharge equal to the peak discharge, i.e., $n$ should be at least equal to 5. Equivalently, assuming $n=5$ and by applying Eq. (2), we can compute $T_{\text {peak }}^{*}$ which is the minimum value of $T_{\text {peak }}$ in order to get the same maximum scour depth, under both steady and unsteady flow conditions, characterized by the same $Q_{\max }$. In other words, if $n=5$ then $T_{\text {peak }}$ should be bigger than 3200 in order to get a similar equilibrium morphology under both steady and unsteady flow conditions.

Nevertheless, it is worth noting that the proposed results are based on specific structure configurations and selected hydrograph shapes. Therefore, the generalization of the proposed methodology to other structure typologies under different flow conditions will require further investigations.

\subsection{Applicative example}

Let's apply the proposed methodology to a real case. Porebianka is a river in Poland in which there is a succession of block ramps. After a flood event, which caused significant erosion in correspondence with hydraulic structures and whose hydrograph is reported in Figure 10, the stilling basin morphology downstream of selected block ramps was surveyed. As it can be observed from Figure 10, the flood event lasted almost 120 hours, the peak discharge 
occurred after almost 24 hours from the beginning of the flood event and was equal to 90 $\mathrm{m}^{3} / \mathrm{s}$. Furthermore, the hydrograph shape is very similar to that simulated in our experimental tests, i.e., the duration of the decreasing discharge phase is almost double of the duration of the increasing discharge phase. In this river, after the flood event, very carefully measurements of the stilling basin morphology downstream of selected block ramps were taken. Therefore, we apply the proposed methodology to one of the selected block ramps. Namely, the selected block ramp is characterized by a bed slope $S=0.0833$. The ramp bed is made of uniform rounded rocks, whose the $D_{50}$ is equal to $1.2 \mathrm{~m}$. The material constituting the stilling basin is also uniform and has the following granulometric characteristics: $d_{50}=0.06 \mathrm{~m}$ and $\rho_{s}=2200 \mathrm{~kg} / \mathrm{m}^{3}$. In addition, at the toe of the ramp, the stilling basin is protected by a few rows made of the same rocks constituting the ramp, which act as a protection sill. The river width is $B \approx 30 \mathrm{~m}$ and the geometry of the sections can be assumed rectangular. After the mentioned flood event, the maximum scour depth measured in the stilling basin was equal to $1.07 \mathrm{~m}$.

Pagliara and Palermo (2010) proposed a methodology and some useful relationships by which it is possible to estimate the maximum scour depth downstream of a block ramp both in the presence and in the absence of a protection rock sill downstream of the block ramp located in different spatial positions. It is worth mentioning that the equations proposed by the authors are valid under constant discharge flow conditions. Namely, for a protected stilling basin, Pagliara and Palermo (2008) proposed the following equation to estimate the maximum nondimensional scour depth $Z_{\max }=z_{\max } / h_{1}$, where $h_{1}$ is the approaching flow depth at the ramp toe:

$$
Z_{\max }=0.58 \cdot S^{0.75} \cdot F_{d 90}^{1.8} \cdot\left(a \lambda^{2}+b \lambda+c\right) \cdot\left(d Z_{o p}^{2}+e Z_{o p}+f\right)
$$

In the previous equation, $F_{d 90}=V_{1} /\left(g^{\prime} d_{90}\right)^{0.5}$ is the densimetric Froude number, where $g^{\prime}=g\left[\left(\rho_{s^{-}}\right.\right.$ $\rho) / \rho$ ] is the reduced acceleration, $V_{1}$ is the average flow velocity at the ramp toe, $\rho_{s}$ and $\rho$ are the channel bed sediment density and water density, respectively. $\lambda$ and $Z_{o p}$ are the nondimensional longitudinal and vertical positions of the rock protection in the stilling basin. $a$, $b, c, d, e$ and $f$ are coefficients depending on the ramp slope $S$ and rock sill position. For the selected ramp in the Porebianka river, Eq. (4) can be re-written as follows, by substituting the values of the coefficients, $\lambda$ and $Z_{o p}$ furnished by Pagliara and Palermo (2008):

$$
Z_{\text {max }}=0.58 \cdot S^{0.75} \cdot F_{d 90}^{1.8} \cdot 0.912
$$


Therefore, the maximum estimated scour depth $z_{\max }=Z_{\max } \cdot h_{1}$ can be easily calculated by applying Eq. (4). It is worth noting that, in order to evaluate $z_{\max }$, the estimation of the parameter $h_{1}$ is required. $h_{1}$ can be estimated using the methodology proposed by Pagliara and Palermo (2010). For this applicative example, $h_{1}$ was found to be equal to $0.673 \mathrm{~m}$ and, thus, $z_{\max }=1.11 \mathrm{~m}$. By comparing the estimated $(1.11 \mathrm{~m})$ and measured $(1.07 \mathrm{~m})$ values of $z_{\max }$, for practical purposes, it can be reasonably assumed that the flood event caused an equilibrium morphology which is essentially similar to that which would occur for a steady flow conditions, for which $Q_{\max }=90 \mathrm{~m}^{3} / \mathrm{s}$. This implies that if we apply Eq. (2), we should get that $t_{\text {peak }}^{*}$ (i.e., the estimated time at which the peak discharge $Q_{\max }$ occurs) should be less than 24 hours. Let's re-write Eq. (2) as follows:

$$
t^{*}{ }_{\text {peak }}=\frac{T_{\text {peak }}^{*} \cdot k \cdot n}{\left[g\left(\left(\rho_{s}-\rho\right) / \rho\right) d_{50}\right]^{0.5}}
$$

Assuming a rectangular section, we have that the corresponding critical depth $k$ for the peak discharge $Q_{\max }=90 \mathrm{~m}^{3} / \mathrm{s}$ is equal to $0.97 \mathrm{~m}$. Therefore, by substituting $T_{\text {peak }}^{*}=3200, \rho_{s}=2200$ $\mathrm{kg} / \mathrm{m}^{3}, \rho=1000 \mathrm{~kg} / \mathrm{m}^{3}, n=5, d_{50}=0.06 \mathrm{~m}, k=0.97 \mathrm{~m}$ and $g=9.81 \mathrm{~m} / \mathrm{s}^{2}$ in Eq. (5), we obtain

$t_{\text {peak }}^{*}=18467$ s, i.e., $t_{\text {peak }}^{*}=5.13$ hours, which is much less than 24 hours Therefore, the proposed methodology seems to be confirmed.

\section{Conclusion:}

This paper analyzed the effect on maximum scour depth of the inflow conditions. Namely, the analysis was conducted in the presence of both stepped gabion weirs and rock sills. References tests, under steady flow conditions, were conducted in order to obtain the reference values of the maximum scour depth occurring in the downstream stilling basin. The same tests were repeated under unsteady flow conditions. The hydrograph adopted to simulate the unsteady flow conditions was characterized by a decreasing discharge phase whose duration is double of the increasing discharge phase. The total duration of the unsteady flow tests varied according to the duration of the selected time step $\Delta t$ during which $Q(t)$ was kept constant. The minimum $\Delta t_{\min }$ was set equal to 1 minute. The same unsteady flow tests were repeated for different values of $\Delta t=n \Delta t_{\min }$, in order to determine for which minimum interval duration there are not significant differences between the unsteady flow tests and the corresponding steady flow tests in terms of equilibrium scour morphology. It was experimentally shown that for $n \geq 5$, the equilibrium scour hole characteristics are essentially the same under both steady and unsteady flow conditions. Furthermore, this paper showed that, under unsteady flow conditions, is not always correct to assume the peak discharge to 
evaluate the maximum scour depth using relationships valid for steady flow conditions. Finally, it was shown that there is a minimum time for the peak discharge to occur in order to get the same equilibrium morphology of an event with constant discharge equal to peak discharge. Further investigations are required to generalize the proposed results, by validating them in the presence of other structure typologies and under different flow conditions. 


\section{References}

Bormann, E., Julien, P. Y. (1991). Scour downstream of grade control structures. Journal of Hydraulic Engineering, 117(5), 579-594, doi: 10.1061/(ASCE)07339429(1991)117:5(579).

Breusers, H.N.C., Raudkivi, A.J. (1991). Scouring. IAHR Hydraulic structures design manual 2, Balkema: Rotterdam, the Netherlands.

Bhuiyan, F., Hey, R. D., Wormleaton, P. R. (2007). Hydraulic evaluation of w-weir for river restoration. Journal of Hydraulic Engineering, 133 (6), 596-609, doi: 10.1061/(ASCE)0733-9429(2007)133:6(596).

D'Agostino, V., Ferro, V. (2004). Scour on alluvional bed downstream of grade-control structures. Journal of Hydraulic Engineering, 130(1), 1-14, doi: 10.1061/(ASCE)07339429(2004)130:1(24).

Essery, I. T. S., Horner M. W. (1978). The hydraulic design of stepped spillways. CIRIA, Report No. 33, London, UK.

Hoffmans, G. J. C. M. (1998). Jet scour in equilibrium phase. Journal of Hydraulic Engineering, 124(4), 430-437.

Hoffmans, G. J. C. M. (2010). Stability of stones under uniform flow. Journal of Hydraulic Research, 136(2), 129-136, doi: 10.1061/(ASCE)0733-9429(2010)136:2(129).

Hoffmans, G. J. C. M., Verheij, H. J. (1997). Scour manual. Balkema: Rotterdam, the Netherlands.

Mason, P. J., Arumugam, K. (1985). Free jet scour below dams and flip buckets. Journal of Hydraulic Engineering, 111(2), 220-235, doi: 10.1061/(ASCE)07339429(1985)111:2(220).

Oertel, M., Peterseim, S., Schlenkhoff, A. (2011). Drag coefficients of boulders on a block ramp due to interaction processes. Journal of Hydraulic Research, 49(3), 372-377, doi: 10.1080/00221686.2011.565695.

Ohtsu, I., Yasuda, Y., Takahashi, M. (2004). Flow characteristics of skimming flows in stepped channels. Journal of Hydraulic Engineering, 130(9), 860-869, doi: 10.1061/(ASCE)0733-9429(2004)130:9(860).

Pagliara, S., Mahmoudi Kurdistani, S. (2015). Clear water scour at J-Hook Vanes in channel bends for stream restorations. Ecological Engineering, 83, 386-393, doi: 10.1016/j.ecoleng.2015.07.003.

Pagliara, S., Mahmoudi Kurdistani, S., Palermo, M., Simoni, D. (2016). Scour due to rock sills in straight and curved horizontal channels. Journal of Hydro-Environment Research, 10, 12-20, doi: 10.1016/j.jher.2015.07.002.

Pagliara, S., Palermo, M. (2008). Scour control downstream of block ramps. Journal of Hydraulic Engineering, 134(9), 1376-1382, doi: 10.1061/(ASCE)07339429(2008)134:9(1376).

Pagliara, S., Palermo, M. (2010). Influence of tailwater depth and pile position on scour downstream of block ramps. Journal of Irrigation and Drainage Engineering, 136(2), 120-130, doi: 10.1061/(ASCE)IR.1943-4774.0000132.

Pagliara, S., Palermo, M. (2011). Effect of stilling basin geometry on clear water scour morphology downstream of a block ramp. Journal of Irrigation and Drainage Engineering, 137(9), 593-601, 137(9), 593-601, doi: 10.1061/(ASCE)IR.19434774.0000331.

Pagliara, S., Palermo, M. (2013). Rock grade control structures and stepped gabion weirs: scour analysis and flow features. Acta Geophysica, 61(1), 126-150, doi: 10.2478/s11600-012-0066-0.

Pagliara, S., Hager, W.H., Unger, J. (2008). Temporal evolution of plunge pool scour. Journal of Hydraulic Engineering, 134(11), 1630-1638, doi: 10.1061/(ASCE)07339429(2008)134:11(1630).

Pagliara, S., Palermo, M., Carnacina, I. (2012b). Live-bed scour downstream of block ramps for low densimetric Froude numbers. International Journal of Sediment Research, 27(3), pp. 337-350, doi: 10.1016/S1001-6279(12)60039-0. 
Pagliara, S., Palermo, M., Roy, D. (2012a). Stilling basin erosion due to vertical crossing jets. Journal of Hydraulic Research, 50(3), 290-297, doi: 10.1080/00221686.2012.669534.

Pagliara, S., Roy, D., Palermo, M. (2010). 3D plunge pool scour with protection measures. Journal of Hydro-Environment Research, 4(3), 225-233, doi: 10.1016/j.jher.2009.10.014.

Parker, G., Klingeman, P. C., McLean D. G. (1982). Bedload and size distribution in paved gravel-bed streams. Journal of the Hydraulic Division, 108(4), 544-571, doi: 10.1061/(ASCE)0733-9429(1983)109:5(793).

Pegram, G., Officer, A., Mottram, S. (1999). Hydraulics of skimming flow on modeled stepped spillways. Journal of Hydraulic Engineering, 125(5), 500-510, doi: 10.1061/(ASCE)0733-9429(1999)125:5(500).

Peyras, L., Royet, P., Degoutte, G. (1992). Flow and energy dissipation over stepped gabion weirs. Journal of Hydraulic Engineering, 118(5), 707-717, doi: 10.1061/(ASCE)07339429(1992)118:5(707).

Rajaratnam, N. (1981). Erosion by plane turbulent jets. Journal of Hydraulic Research, 19(4), 339-358, doi: 10.1080/00221688109499508.

Rajaratnam, N. (1990). Skimming flow in stepped spillways. Journal of Hydraulic Engineering, 116(4), 587-591, doi: 10.1061/(ASCE)0733-9429(1990)116:4(587).

Rajaratnam, N., Macdougall, R. K. (1983). Erosion by plane wall jets with minimum tailwater. Journal of Hydraulic Engineering, 109(7), 1061-1064, doi: 10.1061/(ASCE)0733-9429(1983)109:7(1061).

Robinson, K. M., Rice, C. E., Kadavy K. C. (1997). Design of rock chutes. Transactions of the American Society of Agricultural Engineers, 41(3), 621-626.

Scurlock, S. M., Thornton, C. I., Abt, S. R. (2012). Equilibrium scour downstream of threedimensional grade-control structures. Journal of Hydraulic Engineering, 138(2), 167176, doi: 10.1061/(ASCE)HY.1943-7900.0000493.

Unger, J., Hager, W. H. (2006). Temporal flow evolution of sediment embedded circular bridge piers. Proceedings of River Flow 2006, 729-739.

Whittaker, W., Jaggi, M. (1986). Blockschwellen. ETH, Zurich, VAW Mitteilungen 91.

Veronese, A. (1937). Erosioni di fondo a valle di uno scarico. Annali Lavori Pubblici, 75(9), 717-726. 


\section{List of figures}

Figure 1 Diagram sketch of a stepped gabion weir: (a) Nappe Flow, (b) Transition Flow, and (c) Skimming Flow regime; (d) picture of a stepped gabion weir.

Figure 2 (a) Diagram sketch and (c) picture of a straight rock sill; (b) Diagram sketch and (d) picture of a curved rock sill. The black arrow indicates the flow direction.

Figure 3 Non-dimensional hydrograph adopted for tests with stepped gabion weirs.

Figure 4 Variation of scour depth evolution for different time step discharge increase along with the indication of the coordinates of maximum scour depth occurring for a steady test with discharge equal to $Q_{\max }$. Peak discharge equal to: (a) $Q_{\max }=51 / \mathrm{s}$; (b) $Q_{\max }=61 / \mathrm{s}$; (c) $Q_{\max }=7 \mathrm{1} / \mathrm{s}$; (d) $Q_{\max }=8 \mathrm{1} / \mathrm{s}$; (e) $Q_{\max }=91 / \mathrm{s}$; (f) $Q_{\max }=101 / \mathrm{s}$.

Figure 5 Variation of scour depth evolution for different time step discharge increase along with the indication of the coordinates of maximum scour depth occurring for a steady test with discharge equal to $Q_{\max }$. Peak discharge equal to: (a) $Q_{\max }=10 \mathrm{l} / \mathrm{s}$ and (b) $Q_{\max }=15 \mathrm{l} / \mathrm{s}$ (curved rock sill); (c) $Q_{\max }=10 \mathrm{l} / \mathrm{s}$ and $Q_{\max }=15$ 1/s (straight rock sill).

Figure 6 Variation of maximum non-dimensional scour depth with non-dimensional discharge for different $n$ values and non-dimensional time step discharge increase equal to: (a) $\Delta T=546$; (b) $\Delta T=484$; (c) $\Delta T=436$; (d) $\Delta T=400$; (e) $\Delta T=370$; (f) $\Delta T=345$

Figure 7 Variation of maximum non-dimensional scour depth with non-dimensional discharge for different $n$ values and non-dimensional time step discharge increase equal to: (a) $\Delta T=270$ and (b) $\Delta T=205$ (curved rock sill); (c) $\Delta T=270$ and (d) $\Delta T=205$ (straight rock sill).

Figure 8 Variation of maximum non-dimensional scour depth with non-dimensional time $T$ for different $n$ values and non-dimensional time step discharge increase along with the indication of the non-dimensional time $T$ in which $Q_{\text {peak }}$ is reached: (a) $\Delta T=546$; (b) $\Delta T=484$; (c) $\Delta T=436$; (d) $\Delta T=400$; (e) $\Delta T=370$; (f) $\Delta T=345$

Figure 9 Variation of maximum non-dimensional scour depth with non-dimensional time $T$ for different $n$ values and non-dimensional time step discharge increase along with the indication of the non-dimensional time $T$ in which $Q_{\text {peak }}$ is reached: (a) $\Delta T=270$ and (b) $\Delta T=205$ (curved rock sill); (c) $\Delta T=270$ and (d) $\Delta T=205$ (straight rock sill).

Figure 10 Hydrograph registered during the flood event in Porebianka river (Poland). 
(a)

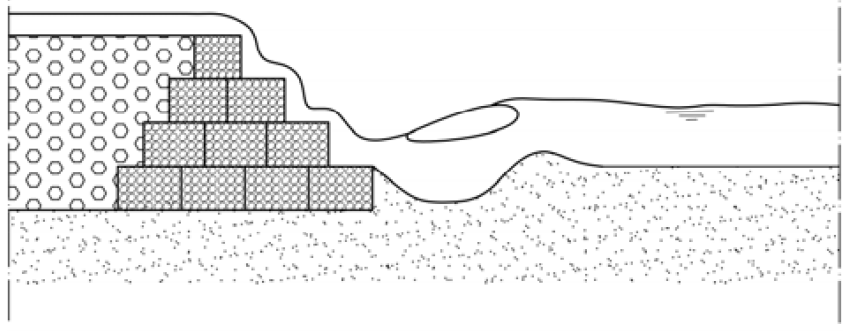

(b)

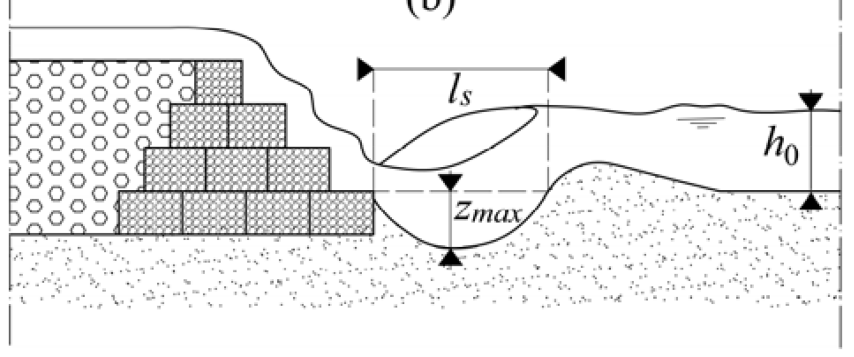

(c)
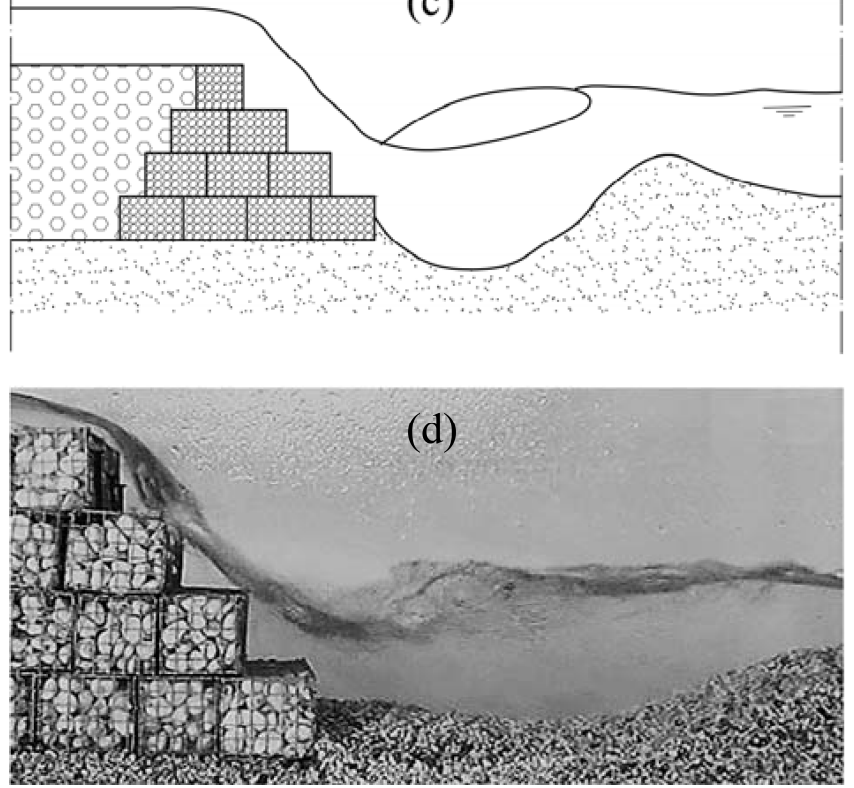

Figure 1 Diagram sketch of a stepped gabion weir: (a) Nappe Flow, (b) Transition Flow, and (c) Skimming Flow regime; (d) picture of a stepped gabion weir. 

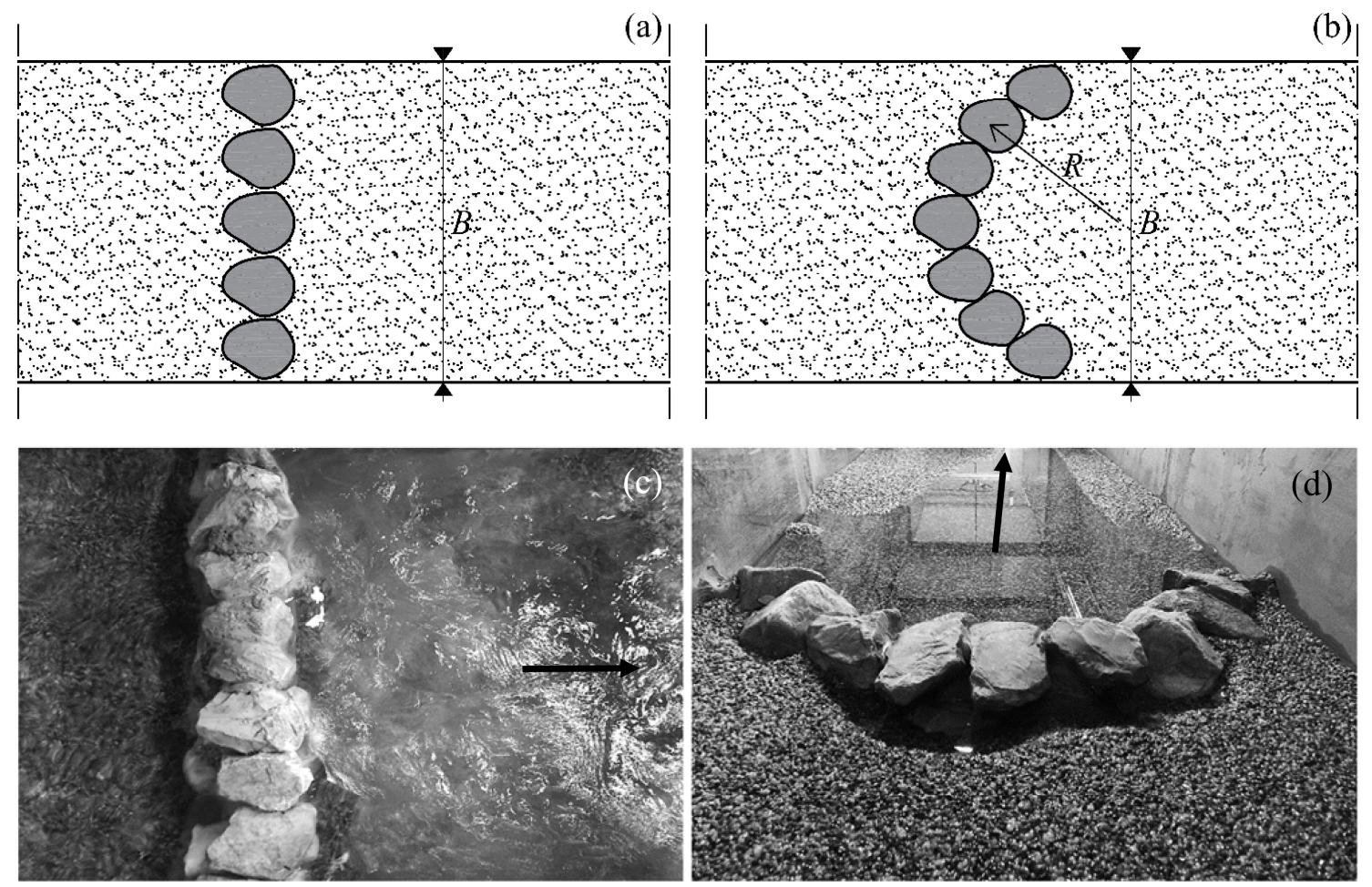

Figure 2 (a) Diagram sketch and (c) picture of a straight rock sill; (b) Diagram sketch and (d) picture of a curved rock sill. The black arrow indicates the flow direction. 


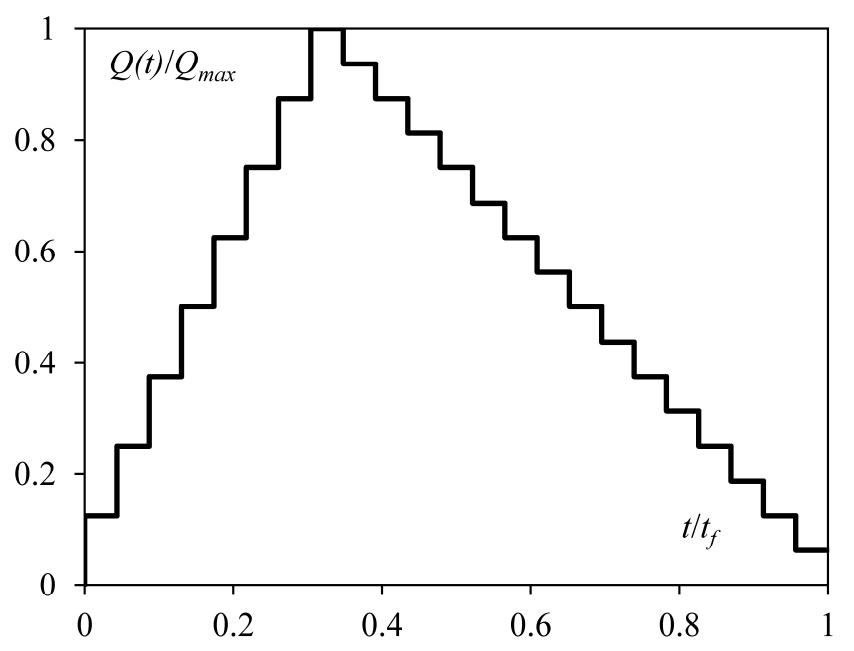

Figure 3 Non-dimensional hydrograph adopted for tests with stepped gabion weirs. 

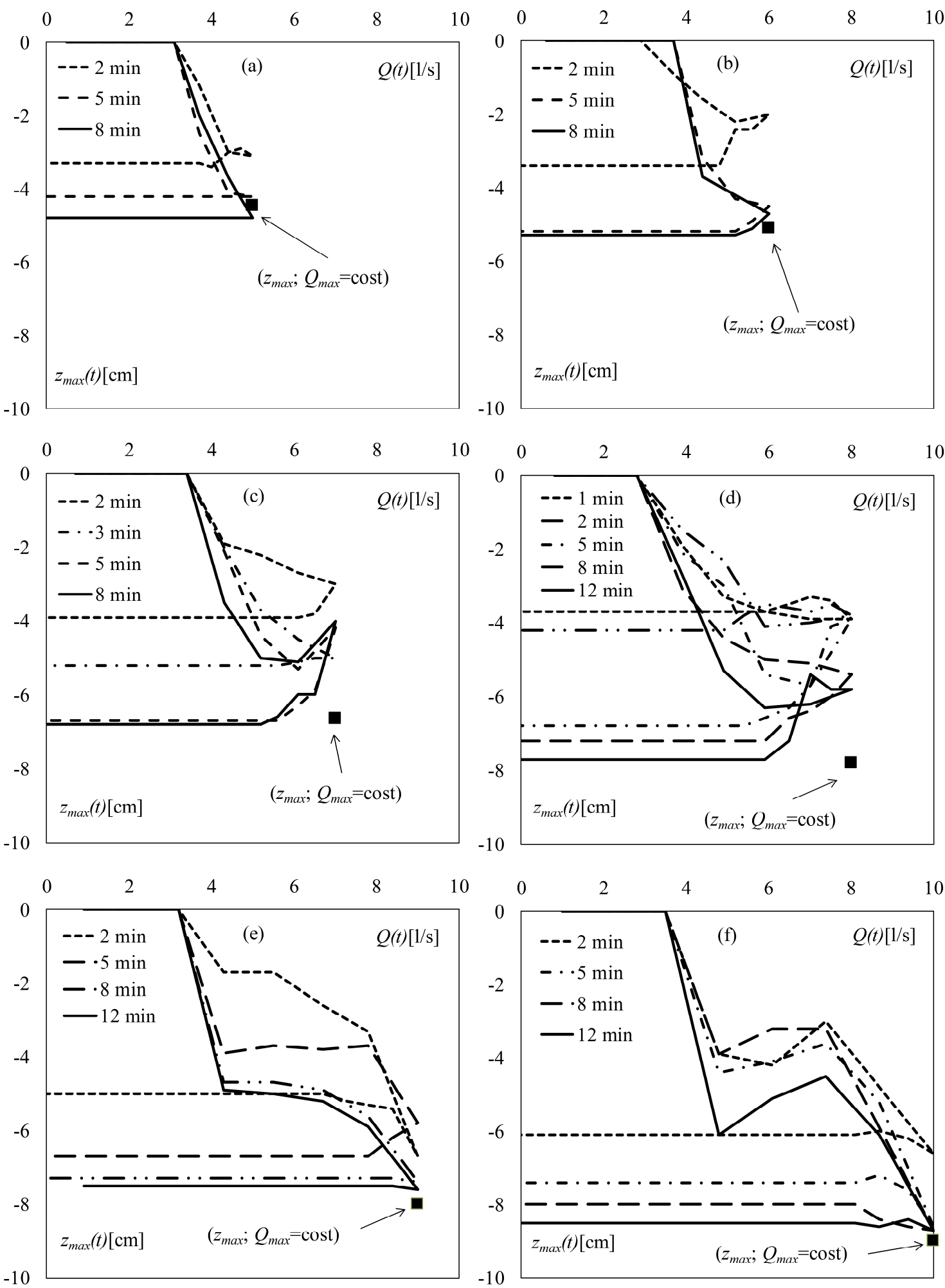

Figure 4 Variation of scour depth evolution for different time step discharge increase along with the indication of the coordinates of maximum scour depth occurring for a steady test with discharge equal to $Q_{\max }$. Peak discharge equal to: (a) $Q_{\max }=51 / \mathrm{s}$; (b) $Q_{\max }=61 / \mathrm{s}$; (c) $Q_{\max }=71 / \mathrm{s}$; (d) $Q_{\max }=81 / \mathrm{s}$; (e) $Q_{\max }=91 / \mathrm{s}$; (f) $Q_{\max }=101 / \mathrm{s}$. 

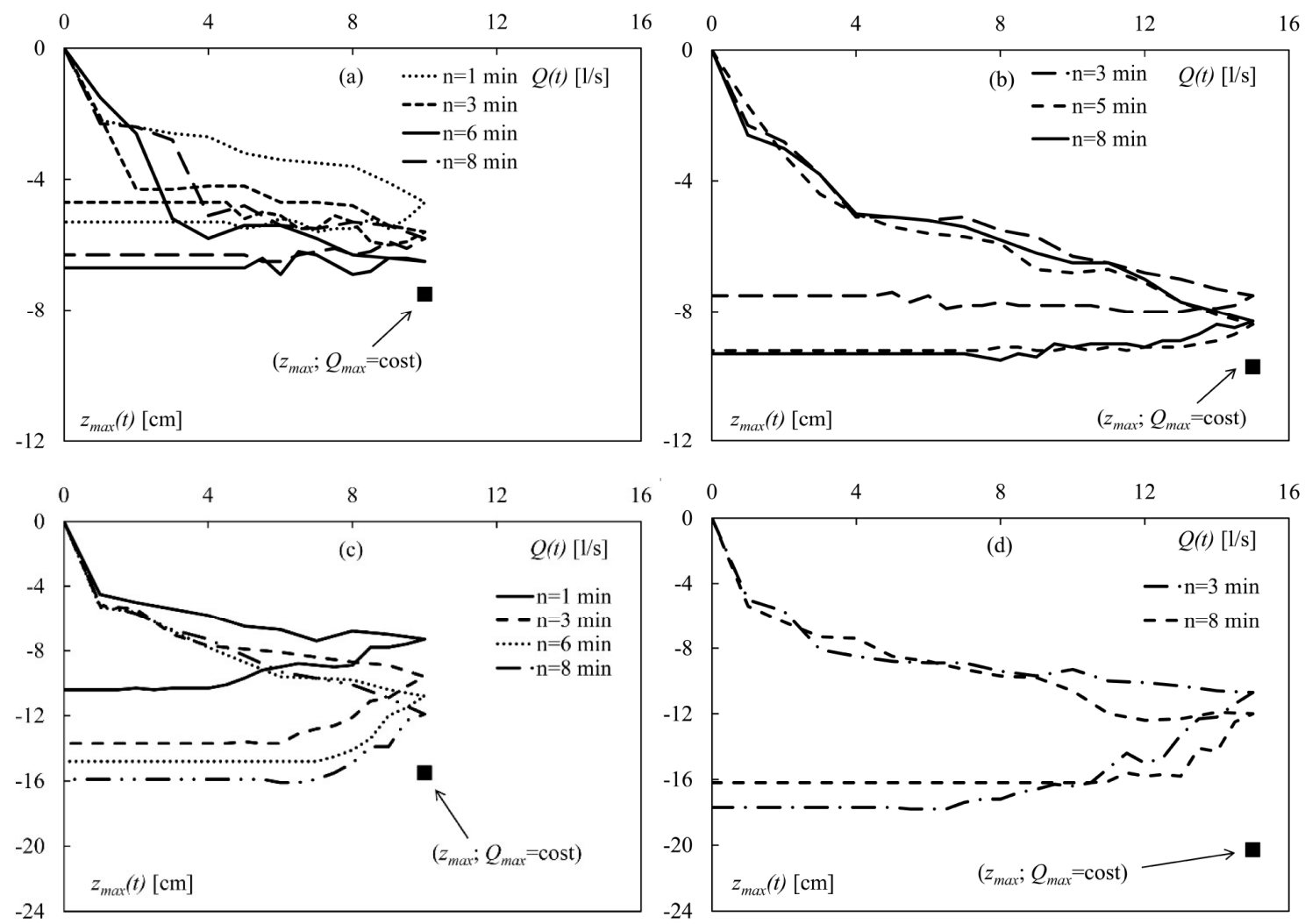

Figure 5 Variation of scour depth evolution for different time step discharge increase along with the indication of the coordinates of maximum scour depth occurring for a steady test with discharge equal to $Q_{\max }$. Peak discharge equal to: (a) $Q_{\max }=10 \mathrm{l} / \mathrm{s}$ and (b) $Q_{\max }=15 \mathrm{l} / \mathrm{s}$ (curved rock sill); (c) $Q_{\max }=101 / \mathrm{s}$ and $Q_{\max }=15$ 1/s (straight rock sill). 

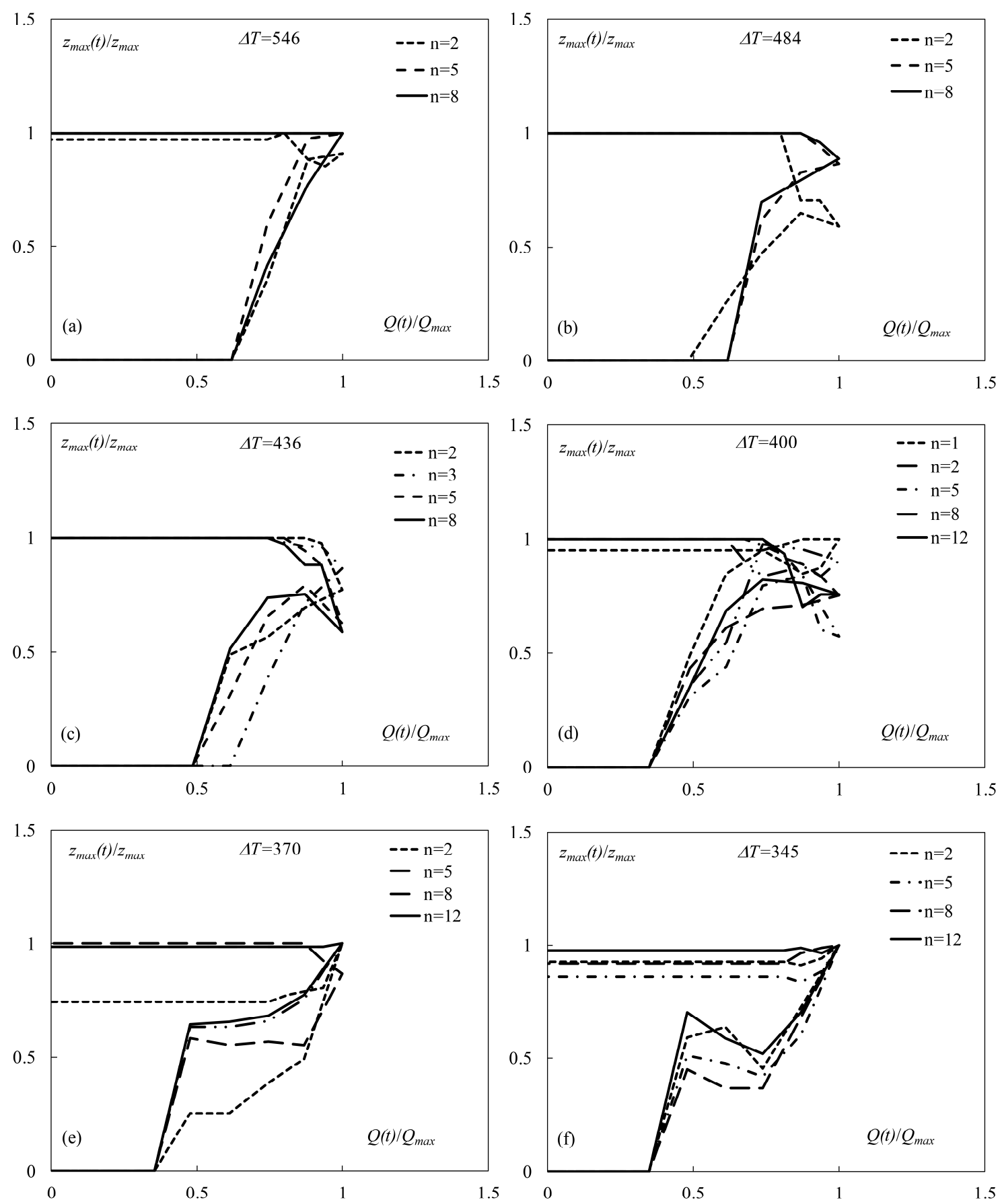

Figure 6 Variation of maximum non-dimensional scour depth with non-dimensional discharge for different $n$ values and non-dimensional time step discharge increase equal to: (a) $\Delta T=546$; (b) $\Delta T=484$; (c) $\Delta T=436$; (d) $\Delta T=400$; (e) $\Delta T=370$; (f) $\Delta T=345$ 

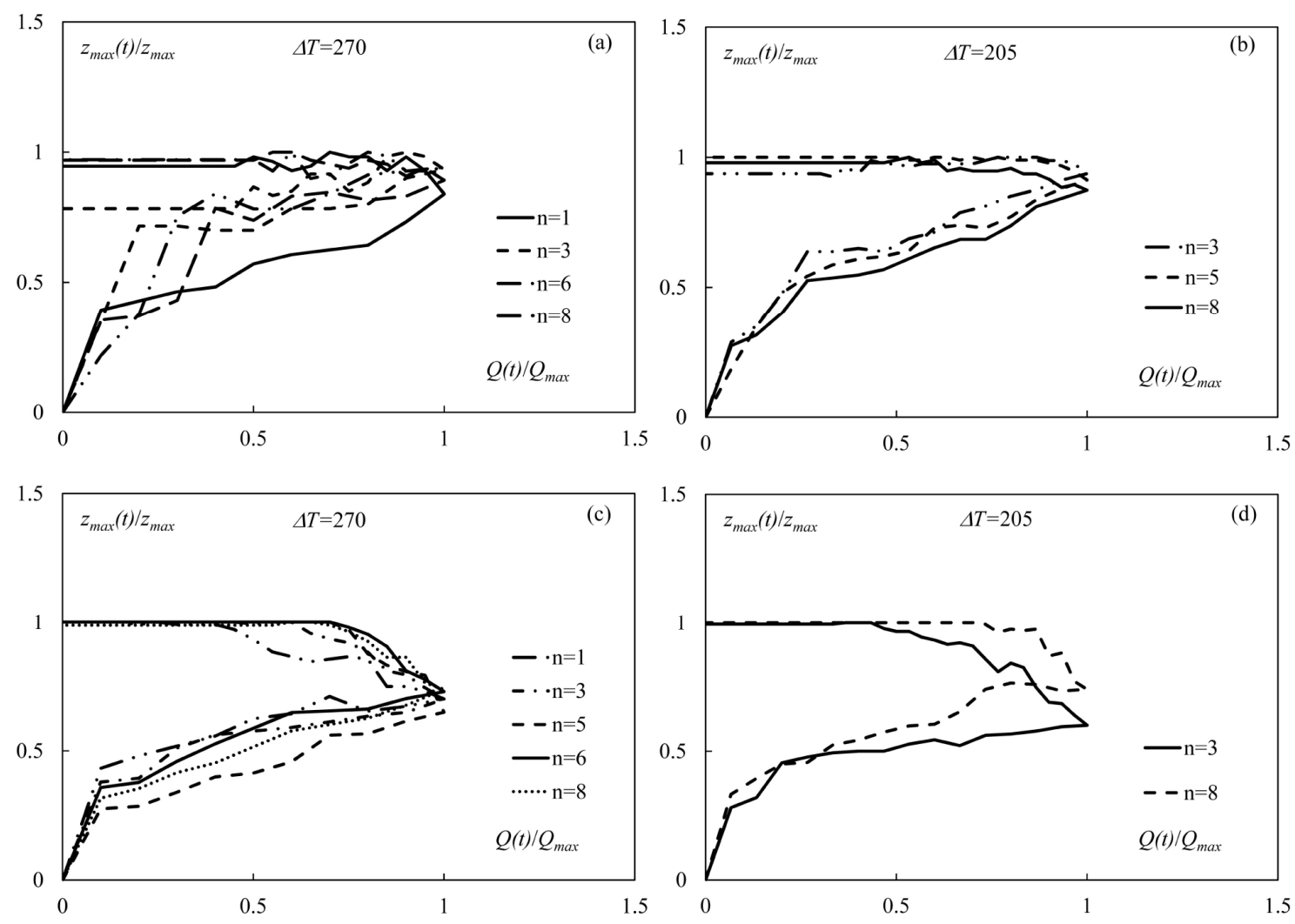

Figure 7 Variation of maximum non-dimensional scour depth with non-dimensional discharge for different $n$ values and non-dimensional time step discharge increase equal to: (a) $\Delta T=270$ and (b) $\Delta T=205$ (curved rock sill); (c) $\Delta T=270$ and (d) $\Delta T=205$ (straight rock sill). 

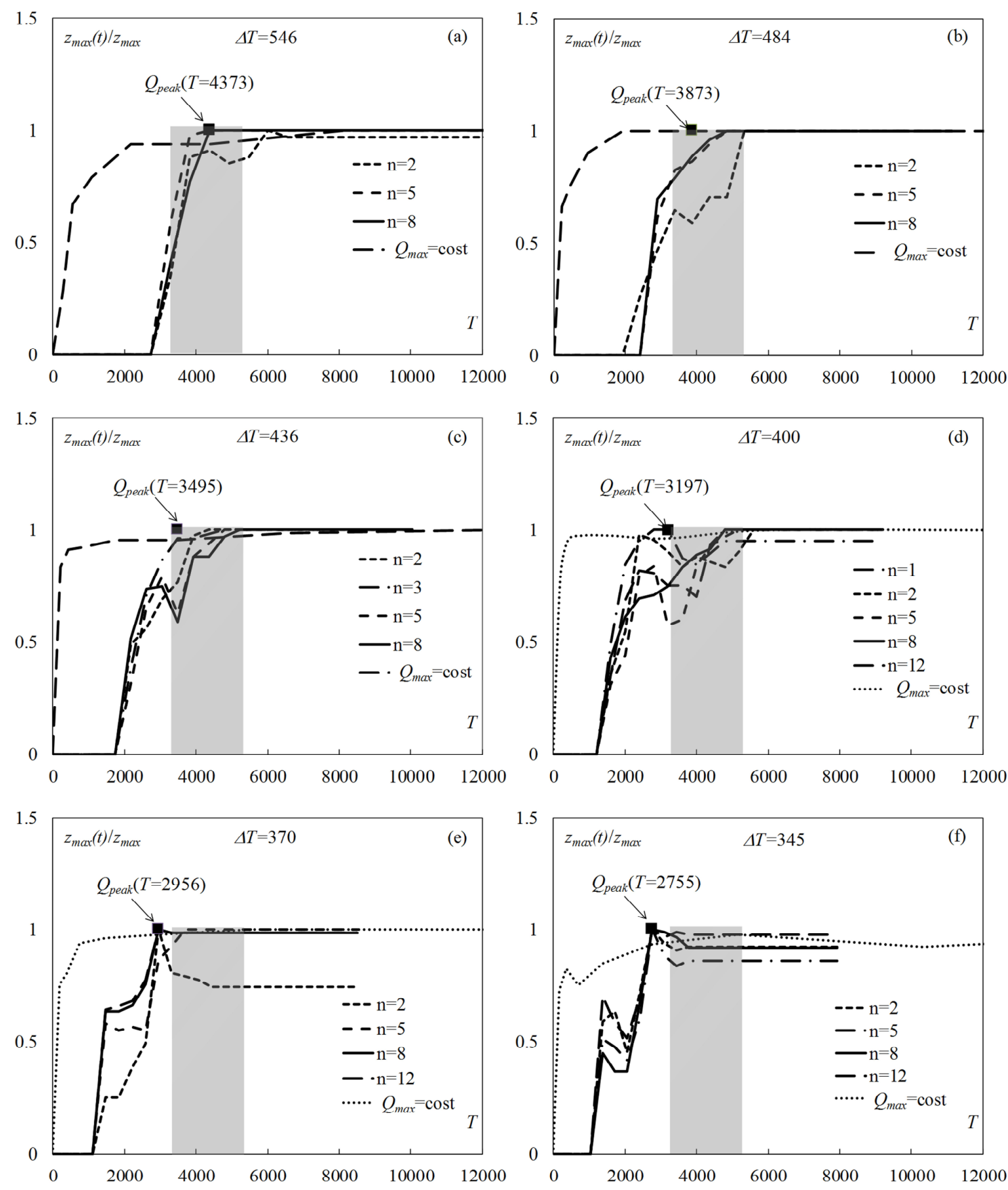

Figure 8 Variation of maximum non-dimensional scour depth with non-dimensional time $T$ for different $n$ values and non-dimensional time step discharge increase along with the indication of the non-dimensional time $T$ in which $Q_{\text {peak }}$ is reached: (a) $\Delta T=546$; (b) $\Delta T=484$; (c) $\Delta T=436$; (d) $\Delta T=400$; (e) $\Delta T=370$; (f) $\Delta T=345$ 

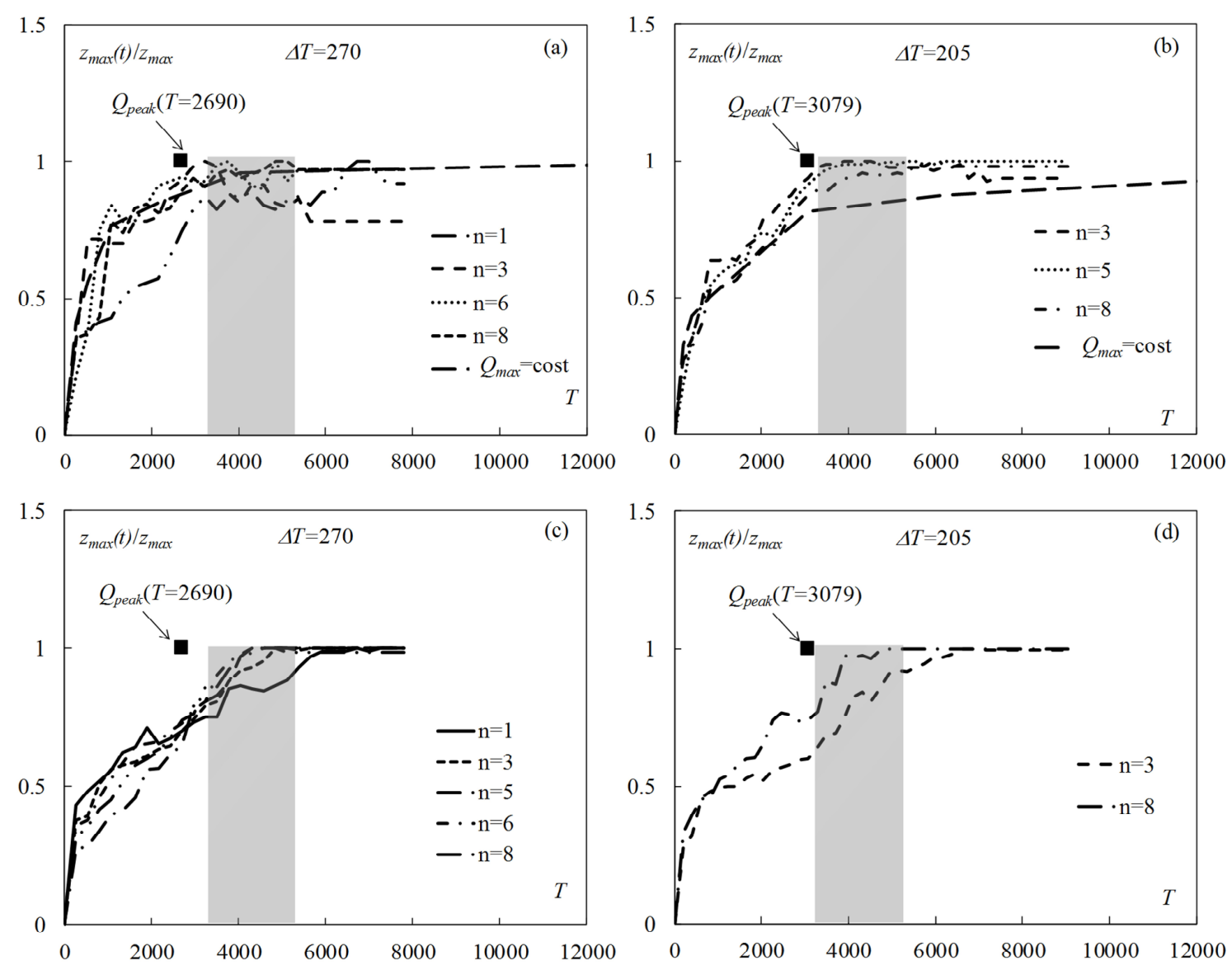

Figure 9 Variation of maximum non-dimensional scour depth with non-dimensional time $T$ for different $n$ values and non-dimensional time step discharge increase along with the indication of the non-dimensional time $T$ in which $Q_{\text {peak }}$ is reached: (a) $\Delta T=270$ and (b) $\Delta T=205$ (curved rock sill); (c) $\Delta T=270$ and (d) $\Delta T=205$ (straight rock sill). 


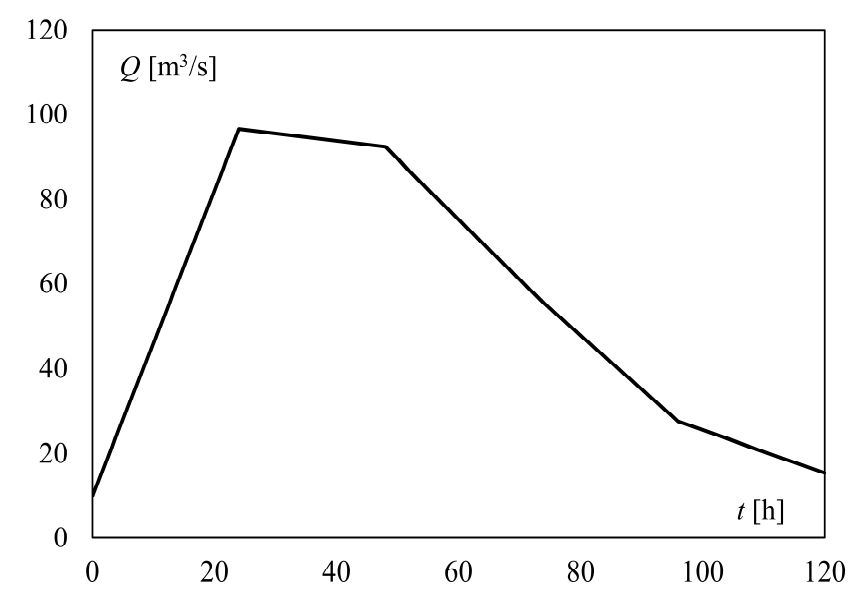

Figure 10 Hydrograph registered during the flood event in Porebianka river (Poland). 